\title{
Geometric Method for Estimating Shading Degree of Objects in Solar Industry
}

\author{
Leonid Markin ${ }^{1}$ and Lyudmila Bobrik ${ }^{1}$ \\ ${ }^{1}$ Moscow Aviation Institute (National Research University), Volokolamskoe Highway 4, Moscow, 125993, Rus- \\ sian Federation
}

\begin{abstract}
The paper presents a geometric model for evaluating the effective area of photovoltaic solar panels, taking into account their shading cast upon the object when it is exposed to a solar flux directed as it has been set. The relevance of such research is due to the fact that solar energy is a source of ecologically clean energy on earth, in space - it is often the only source of life support for inhabited space stations and future extraterrestrial settlements. It describes problem setting, namely physical and mathematical approaches to evaluating energy efficiency of photovoltaic solar panels. To estimate energy efficiency, we have chosen a voxel geometric model which samples the normal working area. The developed voxel geometric model differs from others significantly, namely it employs 4-digit code instead of 2-digit. Such multi-digit feature allows the solving algorithm to "trace" the shade source quickly when calculating the total effective area of photovoltaic solar panels. The paper presents the software implementation of the described geometric model, the graphical shell, and the results of verification of the aforesaid geometric model. The results of its testing (estimates of accuracy and performance) are given. This results showing sufficient accuracy for practice and high speed of calculations (less than 10 seconds of processor time).
\end{abstract}

\section{Keywords}

Geometric models, solar energy, space aircraft, solar panels, effective area, voxel geometric models, graphical shell

\section{Introduction}

Nowadays, the international community devotes a great amount of attention to renewable energy sources. Among them, solar energy heads the list both for economic and environmental reasons. The inexhaustibility of the ecologically clean energy of the Sun determines not only the development of solar energy on Earth, but also its use in space exploration up to the orbit of Mars [1,2].

The use of solar energy acquires a special role in space. Solar energy in space provides power supply without burning large masses of hydrocarbon fuel and oxygen in orbit. In addition, there are no energy losses in the atmosphere and no dust settling on panels that result in reduced energy production on the Earth by up to $40 \%$. This suggests the importance and relevance of research aimed at increasing energy efficiency of solar energy on the Earth and, especially, in space. The results of this study are aimed at accelerating and improving the design quality of solar energy systems. 


\section{Physical and mathematical problem setting aimed at evaluating a shading degree of photovoltaic solar panels and heliostats \\ 2.1. Physical problem setting that pivots on photovoltaic solar panels and heliostats arrangement}

When designing an SCU, there is a question about the methods for evaluating the effective area of photovoltaic solar panels taking into account their inevitable shading by each other and other structural elements of the SCU designed (Figure 1). All this limits the capability profile of the SCU designed significantly.

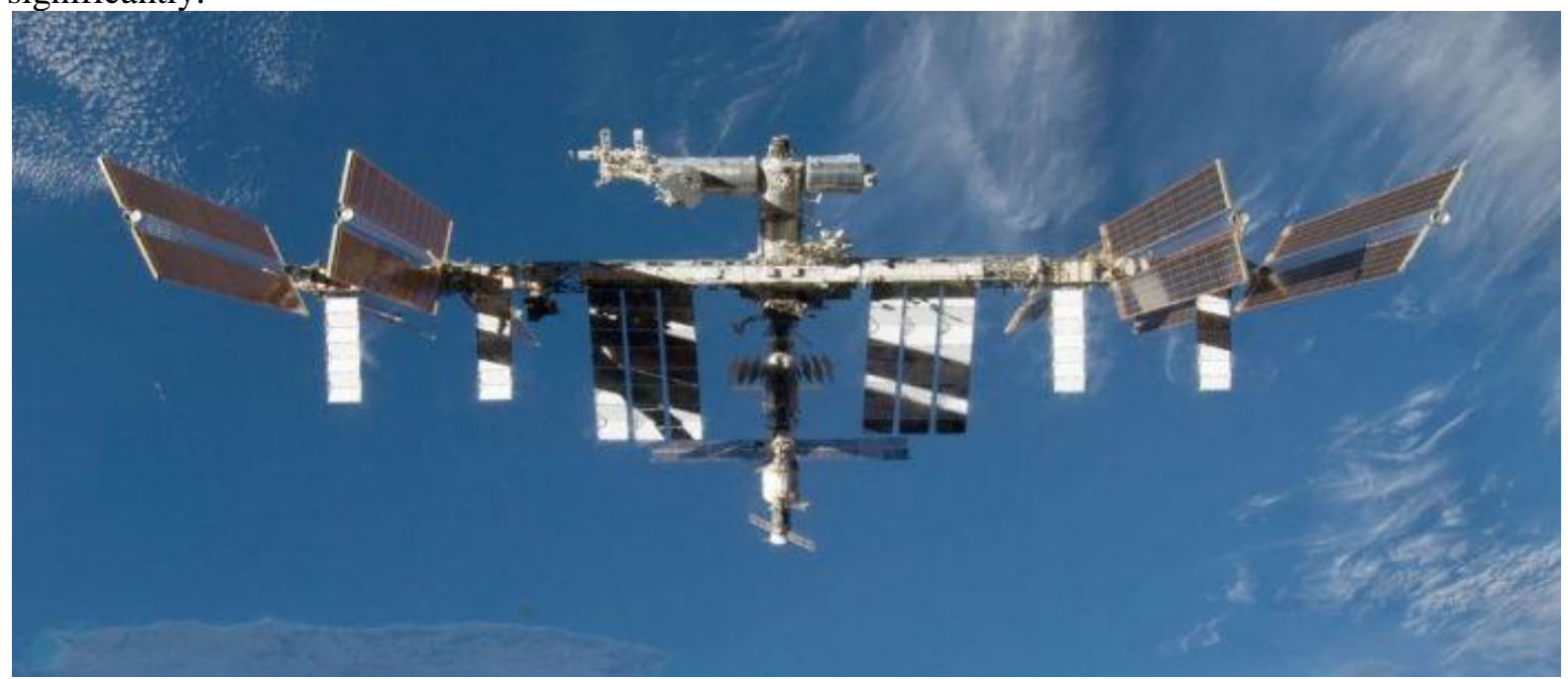

Figure 1: Partial shading of photovoltaic solar panels in space on the International Space Station (ISS)

On the Earth, to prevent mutual shading of heliostats, they are placed at sufficiently large distances from each other, and it takes quite a lot of land. All this indicates the relevance of solving the problem of assessing the degree of mutual shading of solar panels.

\subsection{Mathematical problem setting for evaluating a shading degree of solar panels and heliostats}

Designing SCU or ground-based solar power plants requires solving the optimization problem of determining the area and geometry of solar batteries. Their insufficient area will lead to a power shortage, and excessive ones will lead to ineffective work due to their mutual shading. In the latter case, the costs of their manufacture and the weight of the SCU itself will increase. Therefore, finding a solution to this question can be considered an optimization problem through the lens of mathematical programming.

Our task is to place and orient n solar panels (or heliostats) in a certain space $\Omega$. Let us denote the set of feasible solutions $X$. They are determined by the specific geometry of the solar panels of the SCU and their location relative to the SCU itself from the range of permissible solutions $\Omega$. If the SCU is oriented to the energy flow $\mathrm{W}$ (at any time $t$, each several panel of $n$ photovoltaic solar panels has an energy-absorbing effective area $\mathrm{s}_{i}(t)$, and all together at this time- $\mathrm{S}_{\Sigma}=\sum_{i=1}^{n} \mathrm{~S}_{i}(t)$. Our goal is to obtain at this time (i.e., at the given orientation of the SCU) the maximum solar energy determined by the maximum effective area of the photovoltaic solar panels, which can be written in the following form:

$$
\underset{P_{x} \rightarrow \text { min }}{\operatorname{Max}} S_{\Sigma}(t) \text { для } \mathrm{X} \subset \Omega \cdot
$$

This formula implies that the maximum energy is to obtain under additional restrictions - the variant $X$ of placing heliostats in the range of permissible solutions $\Omega$ and minimizing the energy losses $P_{x}$ 
caused by mutual shading of such photovoltaic solar panels both by solar panels themselves and other elements of the SCU design. It is obvious that the fact that $X$ has to be in the range of permissible solutions $\Omega$ implies many additional restrictions - both general ones (to minimize the occupied area) and specific ones, for example, those that are contingent on non-planar solar-cell panels, areas occupied by additional power elements on them and those that are not involved in obtaining electricity, etc.).

If these photovoltaic solar panels are placed on habitable satellites, our mathematical description may be further complicated by an additional requirement, namely by obtaining the maximum energy not at any particular moment, but for the entire period when the Sun is within the heliostat's visual range, and obtaining the maximum energy flow $\operatorname{Max}_{\Sigma}-$ at a certain time $t_{0}$. It is written in the following form:

$$
\operatorname{Max}_{P_{x} \rightarrow \text { min }} P_{\Sigma}(t) \text { for } \mathrm{X} \subset \Omega^{\circ}
$$

The last formula stipulates the desire to obtain the maximum possible amount of energy for the entire daylight hours at ground stations or the time the Sun is visible on SCU. Let us try to take into account all these factors while describing our geometric optimization model.

\section{Geometric models for evaluating the mutual shading of solar energy ob- jects}

\subsection{Known geometric models for evaluating mutual shading of objects}

Problems with evaluating mutual shading of objects (insolation) have been traditionally addressed in architecture and construction. It is known that the methods currently applied to calculating insolation are commonly divided into two groups: geometric and energy methods [3, 4]. Poorly accurate tools for mechanization applied to insolation calculation such as "insolation ruler", "solar protractor", etc., were invented and widely used. However, even in the $21^{\text {st }}$ century of information technologies, the methods used in perspective geometry underlie modern computer algorithms for calculating insolation.

Energy methods are aimed at direct calculating solar radiation (solar energy) at any specific time in an area with a certain geographical location. Such methods can be used to calculate the energy flux density, the irradiance and exposure created by it in radiant or effective units of measurement.

At the same time, descriptions of shading objects (as a rule, these are boxes of buildings) in both methods of calculating insolation do not require high accuracy and detail. The use of elementary forms in the described methods limits their application to solve the problem we have set. At the same time, the geometric shape of both the SCU themselves and their solar panels is extremely diverse.

The geometric shapes of SCUs and their photovoltaic solar panels are much more complex than building frames. The simplest (with relation to its design concept) linear arrangement of the photovoltaic solar panels on the SCU "Soyuz" (Figure $2 a$ ) can be duplicated lengthways (on the SCU "Rossa"Figure $2 b$ ), as well as by following a circular pattern towards the central axis (on the SCU "Juno"Figure $2 c$ ). As a rule, solar panels are installed on a spacecraft stationary, but they can also rotate, as on the European SCU "Mars-Express" (Figure 2d). These photovoltaic solar panels can also be arranged not coplanar, but at some angle relative to each other (Figure $2 e$ ). 

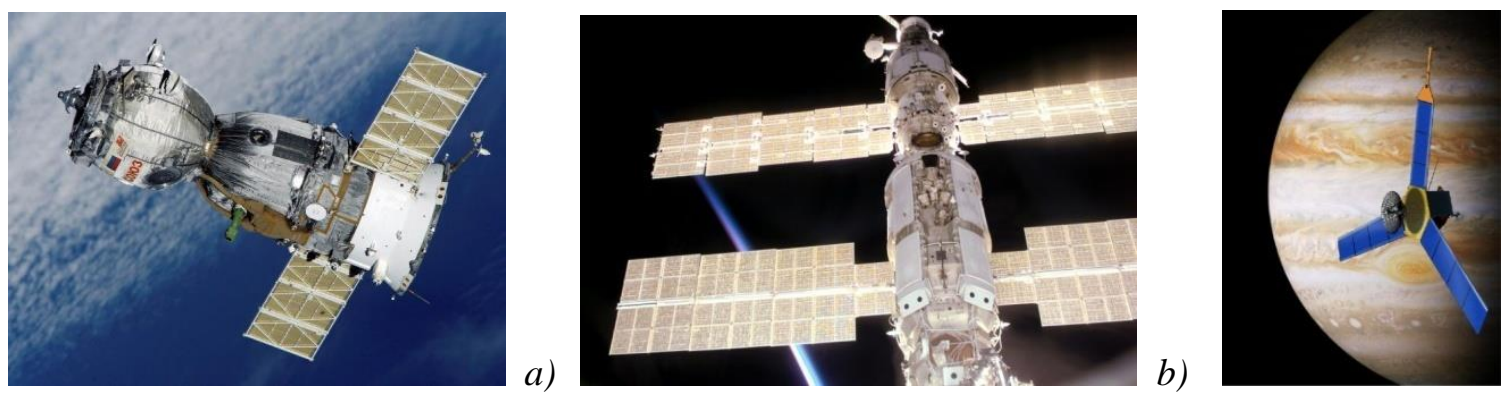

c)
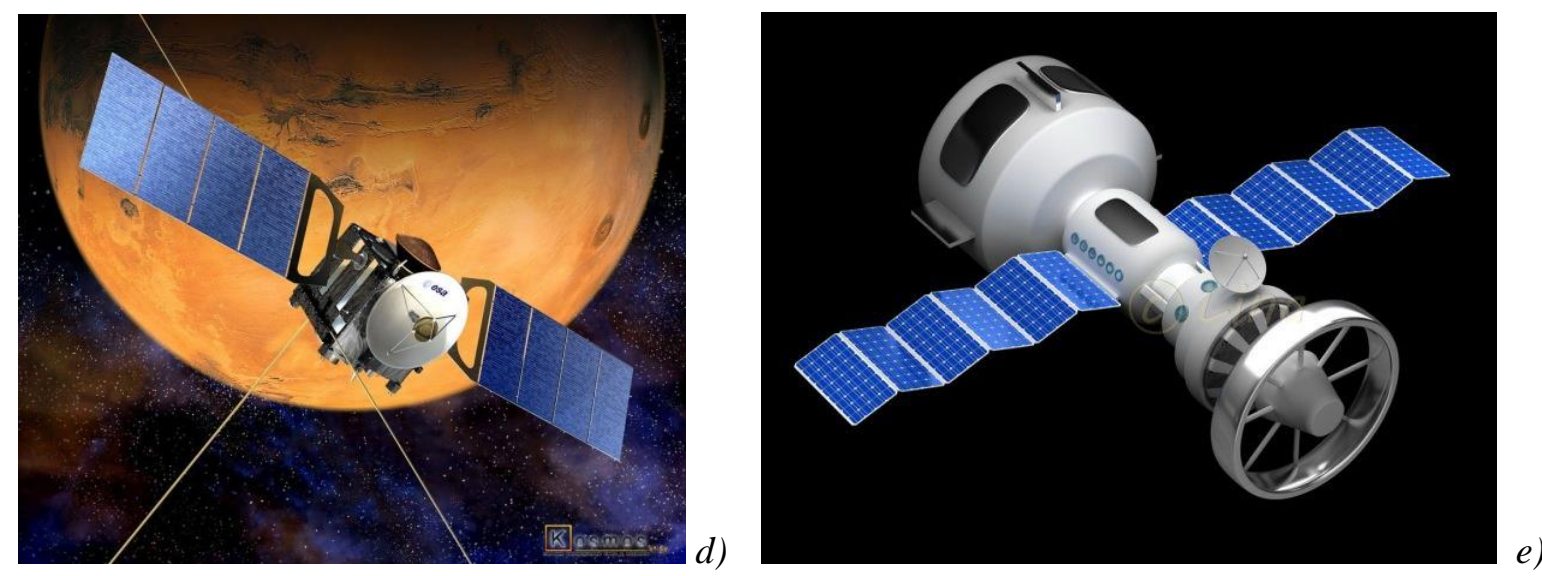

Figure 2: Variants of construction solutions of photovoltaic solar panels on SCUs

\subsection{Voxel geometric models in problems about automated arrangement}

It is a geometric problem in nature how to calculate the impact made by the installed objects on sunbeams transition. Therefore, it is reasonable to solve the problem using the method of geometric modeling [5]. Existing methods of geometric modeling of external shapes of objects allow you to describe any geometric shapes with almost any accuracy.

Design practice shows that in layout tasks, the accuracy of describing the geometric shape of an object is not the main thing [6,7]. The most important property of the geometric model we use is the simplest identification of cases of intersection of the objects being assembled.

From the extensive set of geometric modeling methods, we have chosen to use models sampling the normal working area. It is known that the most accurate description of a geometric body is its identification with the area of space occupied by it. But this is a purely theoretical statement of the problem of the formation of a geometric object (GO). In practice, the initial element of the set $\left(E^{3}\right)$ is not a point, but a cube with dimensions $(l \times l \times l)$. The space $E^{3}$ in this case is called discrete space or voxel space, and any geometric model formed in such space, is called a discrete or voxel model respectively.

The Russian language analogue of the term "voxel" used in foreign scientific literature is the word "receptor", first introduced by D. Zozulevich. [8]. In Russian language literature, the receptor method has other names ("matrix", "binary", "enumeration of space elements", etc.).

The voxel is considered to be unexcited, if the object edge does not pass through it and it does not belong to the internal area (Figure $3 a$ ). Three-dimensional objects are described via a three-dimensional matrix $A=\left\{a_{i, j, k, k}\right\}$ with dimensions $\mathrm{m} \times n \times p$ (Figure $3 b$ ). 

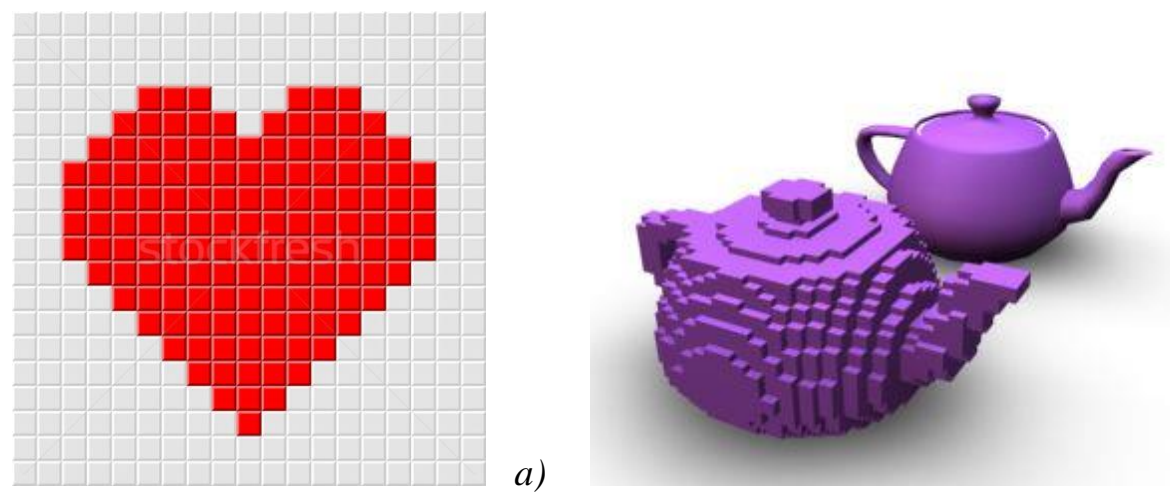

b)

Figure 3: Planar $(a)$ and spatial $(b)$ voxel models

In voxel models, precision in describing the geometric shape of an object is predictably contingent on the chosen sampling rate of the voxel matrix. Limited computer capabilities in the early 70s of the last century did not allow the author of the method, D.M. Zozulevich, to ensure its widespread use. The capabilities of modern computer technology have made it possible to use receptor models to solve various practical problems [9-12].

The voxel method has its advantages and disadvantages. The main one is the need for large amounts of computer memory. Now, increasing computer memory to any size is not a problem. Receptor models fundamentally do not allow us to study the engineering - differential characteristics of the surface of the object (see Figure 3b). This is their fundamental disadvantage, not critical for solving many practical problems.

There is one more problem arising in this context: an engineer never sets any object geometry using voxel models. For him, the initial information is a drawing that defines the types of primitives and their main parameters (that is, a parametric model).

Such parameterization underlies all modern systems of geometric modeling.

Thus, the voxel model can be considered exclusively an "internal machine" one. Therefore, there is a need for an additional software component: "Parametric model" $\leftrightarrow$ "Voxel model". However, there are modern methods used for automatic conversion of a solid model created in any CAD system (for example, SolidWorks) into a voxel model.

\section{Voxel geometric model for evaluating the effective area of photovoltaic so- lar panels}

\subsection{Using a receptor geometric model to estimate the effective area of solar panels}

The methodology for using receptor geometric models is fairly simple and understandable. However, when using them, certain difficulties arise. At present, the difficulties of using receptor models are due to the need to transform the initial parametric model of an object given by the designer into a receptor model, which is an intramachine one. In addition, certain difficulties are presented by the very mathematical processing of receptor models, as well as visualization of the results obtained.

The set task was being solved during working on the thesis research by Kui Min Khan (Republic of the Union of Myanmar), a post-graduate student of the Moscow Aviation Institute (MAI) [13, 14].

In our approach, we use a multivalued receptor matrix to which additional codes have been added. Specifically, it will be three-digit matrix: " 0 "-free space, "1"- -space occupied by the space station, "2"- space occupied by the photovoltaic solar panels (Figure 4). 


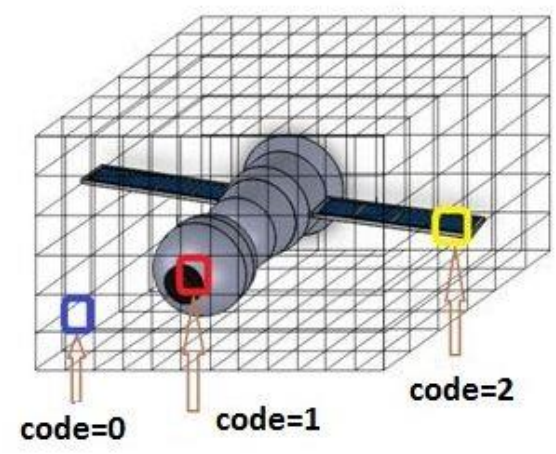

Figure 4: Representation of the SCU using a multi-digit voxel matrix

Let's proceed directly to the calculations of shading. We will move a slice of the voxel matrix that is 1 voxel thick (Figure $5 a$ ) as a cutting plane along the coordinate plane from the beginning to the end of the voxel matrix (Figure $5 b$ ).
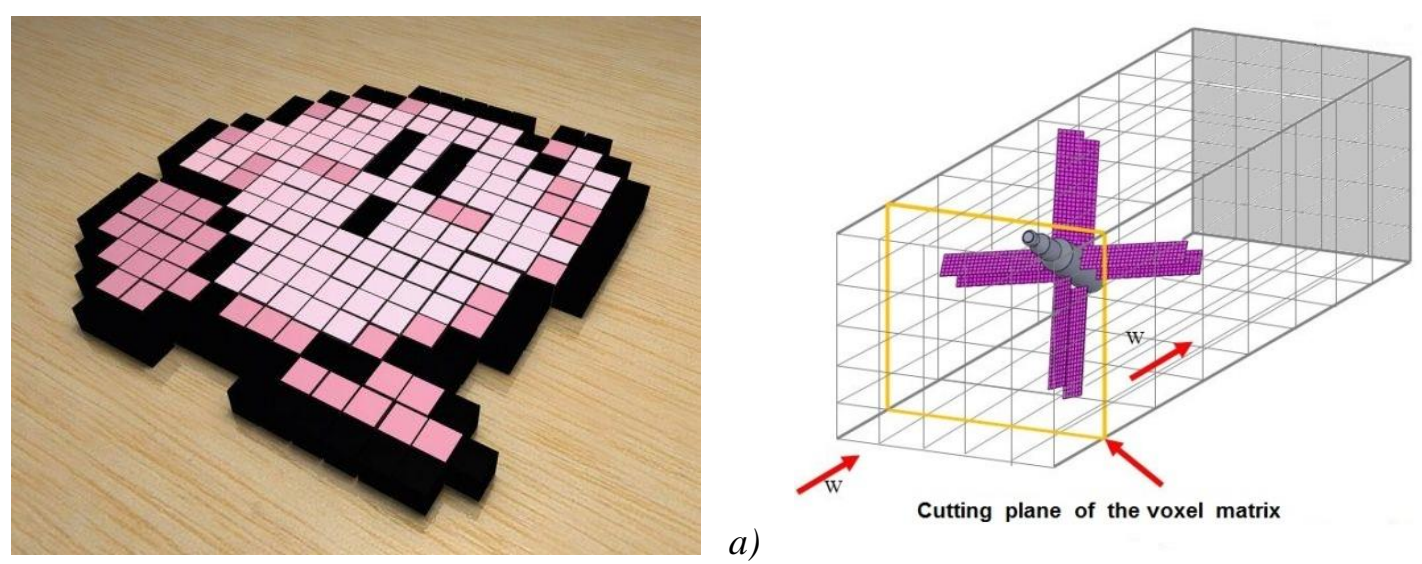

a)

Cutting plane of the voxel matrix

b)

Figure 5: Illustration of a single-layer slice of the receptor matrix $(a)$, displacement of the slice plane along the 3D-matrix $(b)$

On the current slice of the spatial matrix, each receptor is assigned a code " 1 " if its position in space coincides with the SCU body or code "2" if its position in space coincides with the position of one of the solar panels (Figure $6 a$ ). If the current receptor slice does not intersect any elements of the SCU, then the receptor code remains the initially set value "0". A cut of the receptor matrix in a plane perpendicular to the direction of the energy flow W (Figure $6 b$ ) allows us to calculate the total area of inhabited SCU modules overlapping the energy flow (by the number of "1") and the total area of solar panels by the number of receptors with the code "2".

Next, everything seems to be simple - after having summed up the areas of the voxels assigned to the number " 2 " on all slices, we will get the area of the unshaded zones of the photovoltaic solar panels.

There are situations that might occur, if not one, but several layers of the voxel matrix (for example, 4 layers) pass along the thickness of a solar panel, resulting in an unreasonable increase of the effective area of the solar panels by 4 times. It is also necessary to exclude unreasonable repeat accounting of the objects that have been already shielded. To account for shielded objects, we will introduce an additional code " 3 " in the receptor matrix. The main feature of the change introduced into the model is that once a part of the energy flow has been absorbed, it should no longer be taken into account. Therefore, starting with a certain slice of the voxel matrix, all elements following this slice and being assigned to " 2 ", will be assigned to the prohibiting code " 3 " compulsorily, what does not allow to use the voxels assigned to this code in any calculations. 


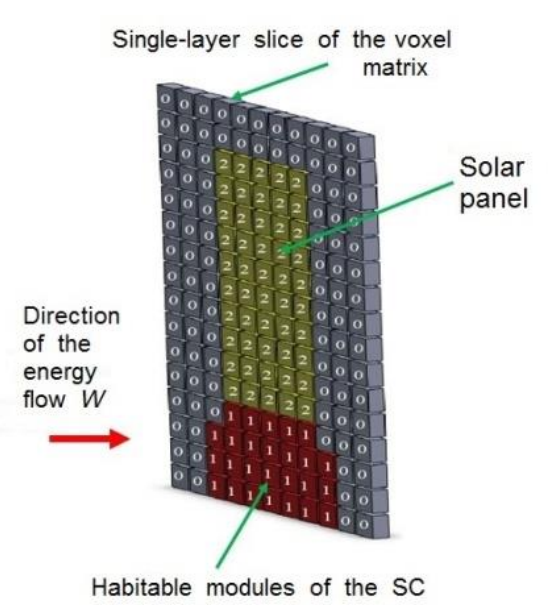

a)

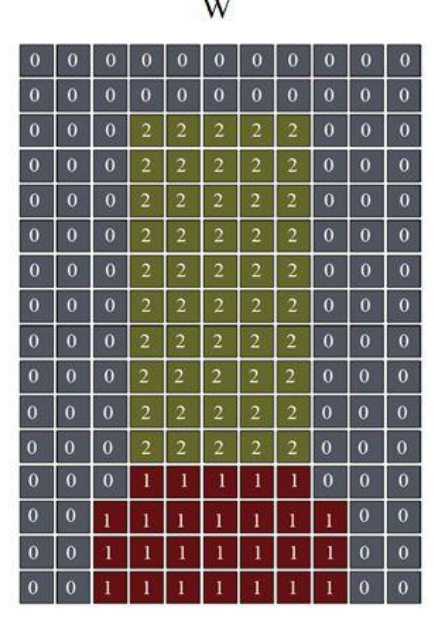

Figure 6: Single-layer slice of the voxel $(a)$, the view of this slice towards the flow (b) b)

However, the shading of the photovoltaic solar panels towards $\mathrm{W}$ that affects their efficiency adversely can be caused not only by other solar panels, but, in some cases, by other elements of the SCU (for example, the body). In addition, immediately after the first detection on the slice of the receptor with the code "3", we will replace with this code the codes of all subsequent receptors in the direction of the energy flow W. As in the previous case, the entire remaining part of the voxel matrix towards the energy flow W is filled with codes " 3 ", and the voxels assigned to this code are not accounted by the calculation of the effective area of the photovoltaic solar panels $S$. Therefore, the voxels assigned to the code "3" are not included in any area calculations, if we use the modified (4-digit) voxel model.

\subsection{Software implementation of the c geometric model}

The geometric model for estimating the effective area of solar panels is implemented as a software package in the $\mathrm{C}$ \# language. At the same time, we have developed a graphical shell that visualizes the calculation process and the calculated parameters of the effective area.

Let's describe the work of the software package. After entering the geometric information in parametric form and converting the parametric model into a receptor model, layer-by-layer scanning of the sections of the receptor matrix begins. Figure $5 a$ shows a $2 \mathrm{D}$ matrix, which in our case is formed as a slice of a 3D matrix moved along the coordinate axis. By scanning each such slice, we calculate the cross-sectional area of the solar panels in this slice and the effective (accumulated) cross-sectional area of the solar panels. As soon as the cutting plane in the receptor matrix began to intercept not only the solar panels, but also the SCU body (Figure $7 c$ ), the calculated values of the SCU body cross-section began to be reflected in the corresponding program window.

After the cutting plane has completely passed through the entire 3D model of the SCU (Figure $7 c$ ), the shading parameters in the program windows will no longer change. Thus, our task has been solved.

One of the advantages inherent to voxel geometric models is their ability to sum the voxel values quickly. Thus, for each specific geometry of solar cells of SCU and their specific orientation relative to the direction of the solar energy flow, the effective area is calculated for each slice of the flat receptor matrix as the total area of receptors with the code "2" (Figure $6 b$ ). The operation of the software package in $\mathrm{C \#}$ is possible with any complexity of the geometry of the spacecraft and its orientation relative to the Sun (Figure 8).

This Figure shows the calculation results as the cutting plane moves along the matrix slice. 


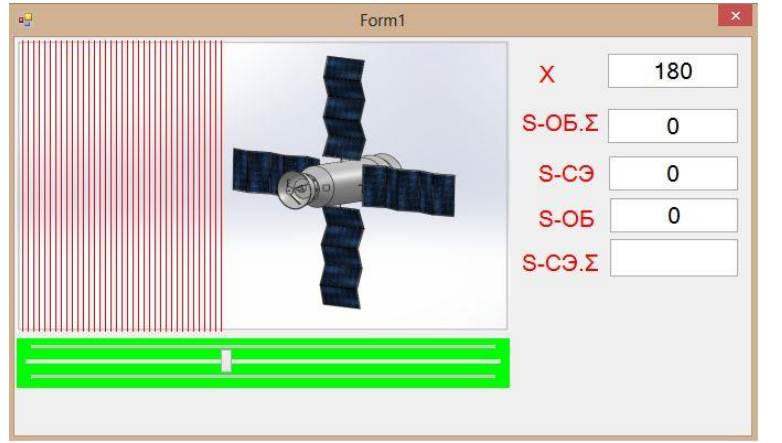

a)

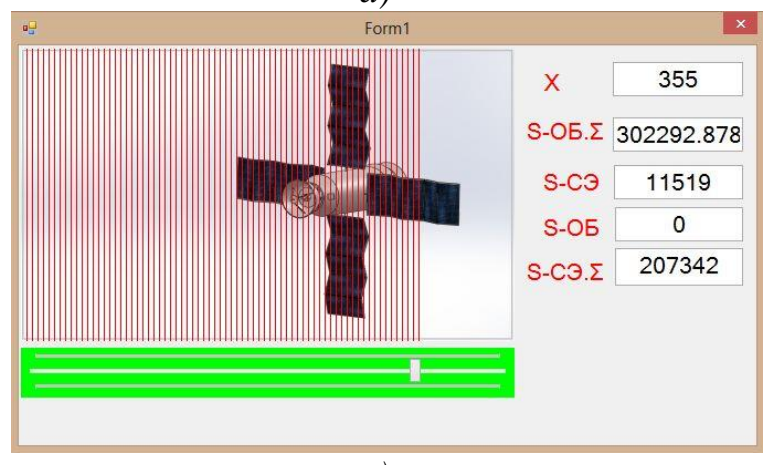

c)

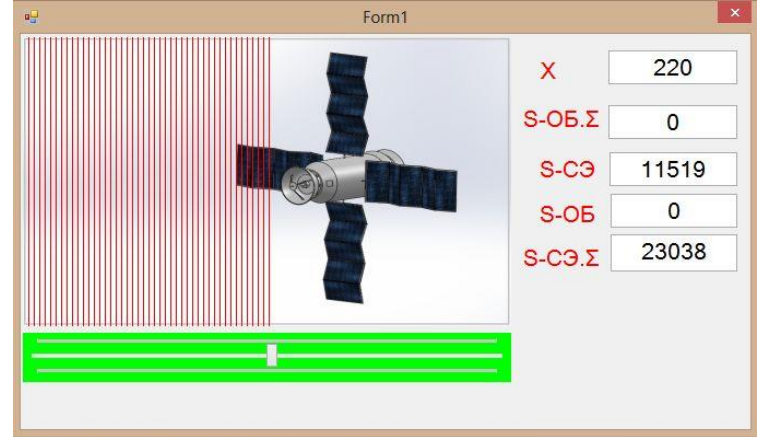

b)

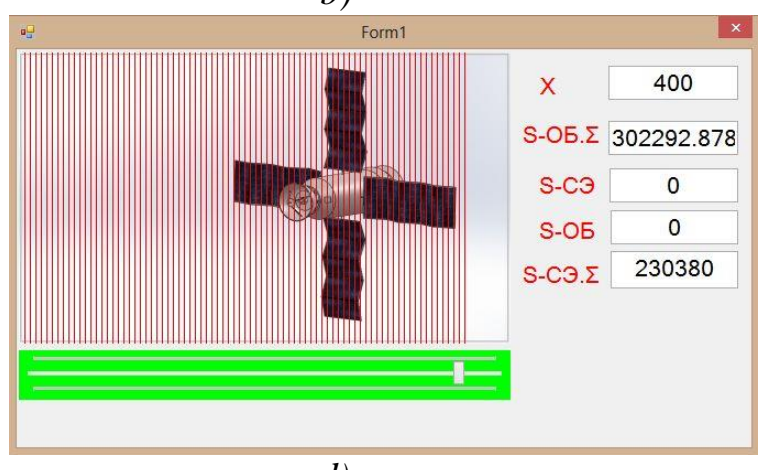

d)

Figure 7: Visualization of calculated current and accumulated cross-sectional areas of solar panels SCU

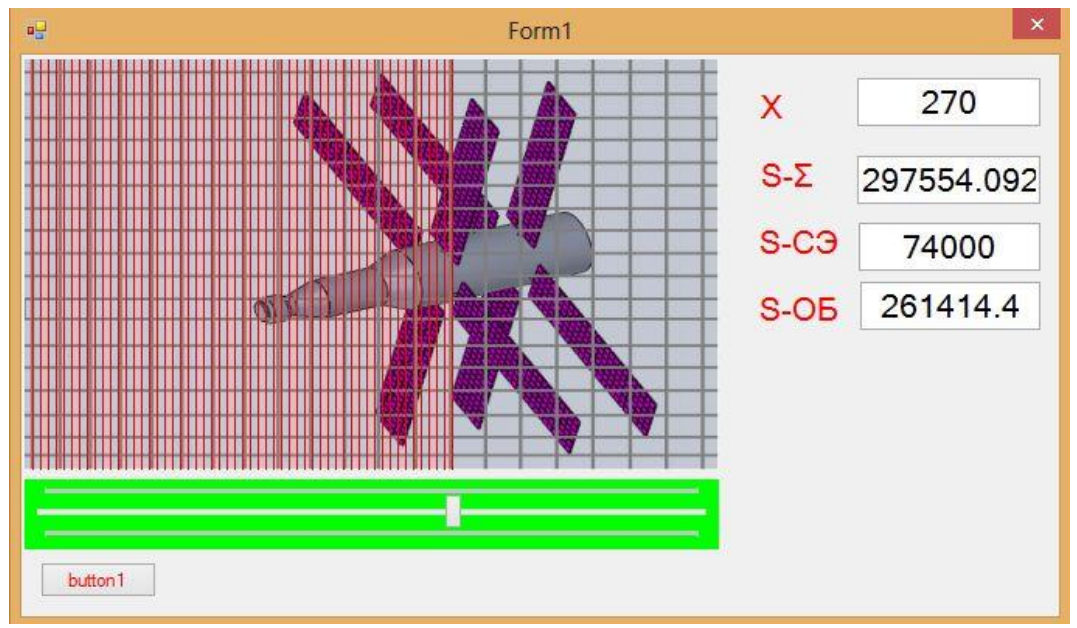

Figure 8: The process of calculating the effective area of solar panels

\subsection{Estimation of the accuracy and efficiency of the implementation of the chosen geometric model}

We will carry out verification of the developed method according to the test model of the SCU with previously known results. To do this, we will test a paddle model implemented in C\# to calculate a structure with pre-known parameters of the effective illuminated area. Thus, the calculated area for the test SCU with the known theoretical values of the $S$-effective (unshaded) surface of solar panels installed on the SCU is shown in Figure 9.

Figure 9 demonstrates the correctness of the geometric model, since the regression curve does not deviate from the theoretical area of solar panels.

Increasing the size of the receptor is expected to reduce the accuracy of calculations. It can be seen that the calculated values are almost symmetrical to the theoretical curve with nominal values. We explain this by a feature of a discrete algorithm for calculating the effective area of solar panels. 


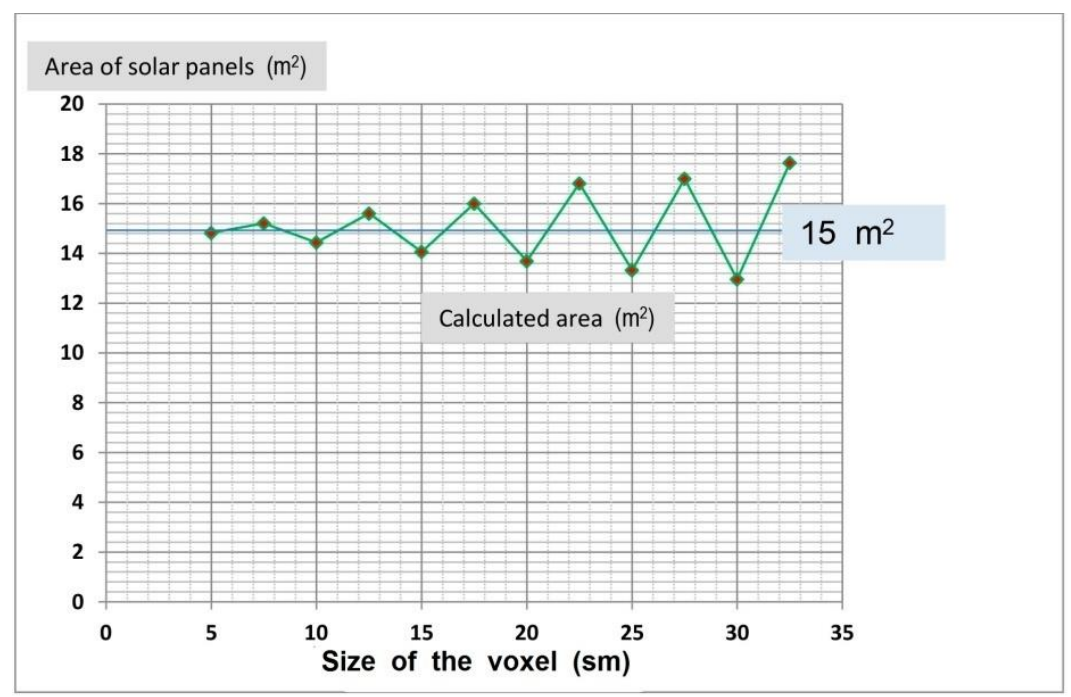

Figure 9: Results of the calculated experiment for the panels area of $15 \mathrm{~m}^{2}$

Obviously, increasing the accuracy of calculations by reducing the size of the receptors will lead to an increase in the calculation time. The compared accuracy and time of the calculations (processor time) are presented in Figure 10. It should be noted that we have used a personal computer (PC) with performance characteristics slightly above average to conduct the calculations.

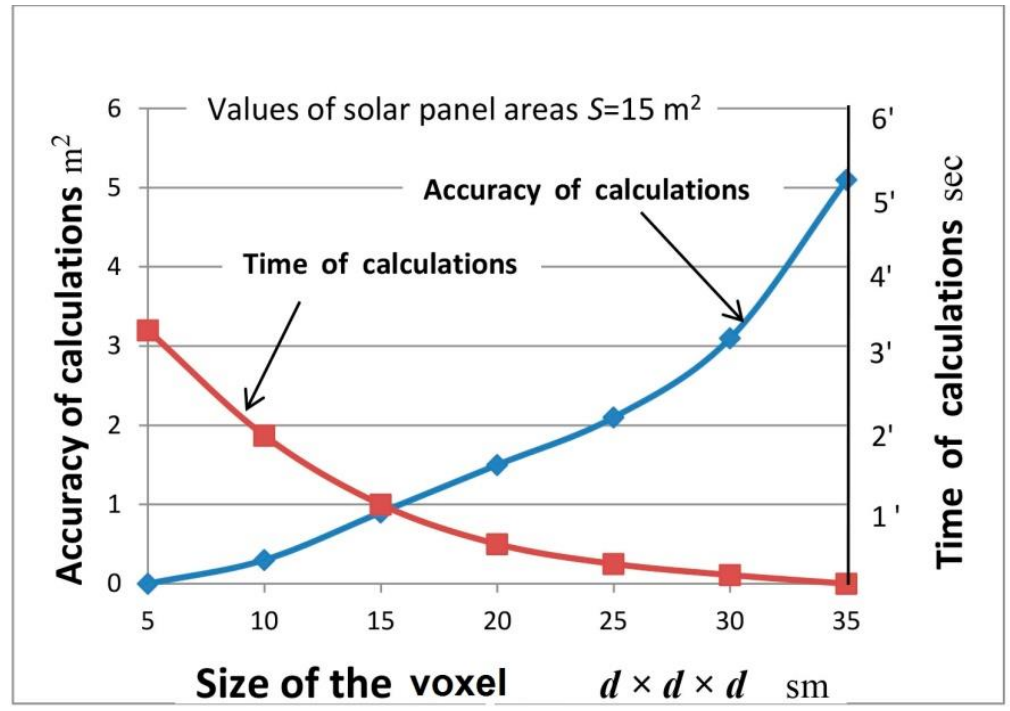

Figure 10: Results of a computational experiment for a solar panel with an area of $15 \mathrm{~m}^{2}$

From this it can be concluded that reducing the size of the receptor significantly increases the accuracy of calculations and slightly slows down the speed of calculations. From this figure it can be seen that with a total area of solar panels of $15 \mathrm{~m}^{2}$, the size of the receptor of $5 \mathrm{~cm}$ provides an absolute error in calculating the effective area of $0,3 \mathrm{~m}^{2}$. With a calculation time of 3,2 seconds, their relative error is $2 \%$ acceptable for practice.

The uniformity of the computational operations performed using only the RAM of a personal computer causes such a small processor time for the implementation of receptor geometric models. At the same time, for the computer implementation of our geometric model, we see the possibility of further reducing the computation time or increasing the accuracy of the results obtained without increasing the time spent. 
But as for the calculation time (less than 10 seconds of the processor time) and the accuracy of the calculation of the result (tenths of a percent), the obtained results, according to experts, can be considered quite acceptable for practical use.

\section{Conclusion}

The conducted research allows us to draw the following conclusions:

- the method of geometric modeling allows us to consider the estimation of the effective area of solar panels as an optimization layout problem;

- receptor (voxel) geometric models have shown their effectiveness in solving a number of specific problems, which, in particular, include insolation problems;

- evaluation of the accuracy and performance of receptor geometric models showed an acceptable time for solving technical tasks (up to 10 seconds of processor time);

- ways of widespread introduction of receptor (voxel) models into design practice, we see their use as internal modules in common geometric modeling systems (SolidWorks, AutoCAD, COMPASS, etc.).

\section{References}

[1] V.I.Vissarionov, G.V.Deryugina, V.A.Kuznecova, N.K.Malinin, Solnechnaya energetika [Solar energetics], Izdatel'skij dom MEI Publ., Moscow, 2011.

[2] G.G.Rajkunov, V.M.Mel'nikov, A.S.CHebotaryov, Orbital'nye solnechnye elektrostancii kak perspektivnyj put' resheniya energeticheskih i ekologicheskih problem [Orbital solar power plants as a promising way to solve energy and environmental problems]. Teploenergetika [Heat power engineering] 11 (2011) 33-38.

[3] V.A.Karataev, E.V.Adonkina, M.G.Ten, S.A.Nefedova, Insolyaciya pomeshchenij i territorij [Insolation of premises and territories], NGASU (Sibstrin) Publ., Novosibirsk, 2013.

[4] N.V.Obolenskij, Arhitekturnaya fizika [Architectural Physics], Arhitektura-S Publ., Moscow, 2007.

[5] N.A.Sal'kov, Geometricheskaya sostavlyayushchaya tekhnicheskih innovacij [The geometric component of technical innovation], Geometriya i grafika [Geometry and graphics] 18(2) (2018) 85-94.

[6] M.Y.Kuprikov, L.V.Markin, Geometricheskie aspekty avtomatizirovannoj komponovki letatel'nyh apparatov [Geometric aspects of the automated layout of aircraft], Geometriya i grafika [Geometry and graphics] 18(3) (2018) 69-87.

[7] L.V.Markin, Kui Min Han, E Vin Tun, G.V.Korn, Receptornye modeli v zadachah avtomatizirovannoj komponovki tekhniki [Receptor models in tasks of automated layout of equipment], Lambert Publ., Saarbryuken, 2016.

[8] D.M.Zozulevich, Mashinnaya grafika v avtomatizirovannom proektirovanii [Computer graphics in computer aided design], Mashinostroenie Publ., Moscow, 1976.

[9] A.V.Tolok, N.B.Tolok, Mathematical Programming Problems Solving by Functional Voxel Method, Automation and Remote Control 79(9) (2018) 1703-1712 (345-354). doi: 10.1134/S0005117918090138

[10] V.M.Abashev, V.V.Bodryshev, N.P.Korzhov, O.S.Tarasenko, Study of interaction of a jet with supersonic flow on the parameter of the intensity of the video frame image (Estudo da interacao de corrente com o fluxo supersonico de acordo com o parametro da intensidade da imagem de video) Periodico Tche Quimica 1 (2018) 348-358.

[11] N.A. Bulychev, V.V.Bodryshev, L.N.Rabinskiy, Analysis of geometric characteristics of twophase polymer-solvent systems during the separation of solutions according to the intensity of the image of micrographs, Periodico Tche Quimica, WoS RFBR №19-08-01023, (2019), 551-559.

[12] L.V.Markin, Receptor (Voxel) geometric models in the tasks of automated layout. The Asian International Journal of Life Sciences, Asia Life Sciences Supplement 19(1) (2019) 125-138. 
[13] Kui Min Han, L.V.Markin, Raschet vzaimnogo zateneniya solnechnyh antenn kosmicheskih letatel'nyh apparatov [Calculation of mutual shading of solar antennas of spacecraft], Elektronnyj zhurnal "Trudy MAI" [Electronic journal "Transactions of Moscow Aviation Institute"] 93 (2017). URL: http://trudy.mai.ru/published.php?ID=80474.

[14] Kui Min Han, Matematicheskoe i programmnoe obespechenie rascheta zatenennosti solnechnyh batarej kosmicheskih letatel'nyh apparatov [Mathematical and software for calculating the shading of solar panels in spacecraft], Master's thesis, Moscow Aviation Institute (National Research University), Moscow, Russian Federation, 2018. 